\title{
Synthesis and characterization of tough foldable and transparent poly(styrene-co-butyl acrylate)/nanoporous cellulose gel (NCG) nanocomposites
}

\author{
J. S. Borah, D. S. Kim* \\ Department of Chemical Engineering, Chungbuk National University, 1 Chungdaero Seowongu Cheongju, 28644 \\ Chungbuk, Korea
}

Received 6 February 2017; accepted in revised form 20 April 2017

\begin{abstract}
Poly (styrene-co-butyl acrylate)/nanoporous cellulose gel nanocomposites [P(St/BA)/NCG] were synthesized by in-situ polymerization of styrene/butyl acrylate (St/BA) monomer mixtures in nanoporous regenerated cellulose gels. The three-dimensional nanoporous cellulose gels (NCGs) were fabricated via dissolution and coagulation of cellulose from aqueous sodium hydroxide $(\mathrm{NaOH})$ /urea solution. The NCG contents in nanocomposites were controlled between 16 and $44 \% \mathrm{v} / \mathrm{v}$ by changing water content of starting hydrogels via compression dewatering. Scanning electron microscopy (SEM) analysis showed that the interconnected nanofibrillar network structure of NCGs was preserved well in the nanocomposites after insitu polymerization. The resulting nanocomposites exhibited excellent transparency (up to $82 \%$ ) in the visible region and high mechanical strength, with a tensile strength of up to $56.0 \mathrm{MPa}$, Young's modulus of up to $2195 \mathrm{MPa}$ and elongation at break up to $80.9 \%$. Dynamic mechanical analysis (DMA) showed a remarkable improvement (by over 3 orders of magnitude) in tensile storage modulus above glass transition temperature of the copolymer. The nanocomposites also showed significant improvements in thermal stability as well as water resistance over NCG.
\end{abstract}

Keywords: polymer composite, nanocomposites, cellulose hydrogels, in-situ polymerization, transparent flexible film

\section{Introduction}

Cellulose is the most abundant naturally occurring polysaccharide, and is considered an almost inexhaustible source of raw material for the ever-increasing need for biocompatible, biodegradable, environmentally friendly products. For decades, cellulose fibers have been used as reinforcing materials in polymer composites [1-12]. In recent years, micro- and nano-scale cellulose fibers have attracted great interest of academic and industrial scientist due to their remarkable physical properties, low cost, low density, high specific strength and stiffness, low thermal expansivity and sustainability. Moreover, the hydroxyl groups on cellulose provide many possibilities for chemical modification of nanofiber surfaces useful in nanocomposite preparation [12-19]. Several researchers have reported on successful compatibilization and preparation of cellulose (nanofillers/ nanowhisker with native cellulose crystallinity) nanocomposites through surface modification by covalently bound hydrophobic groups, surfactant adsorption and direct dispersion from aqueous suspension using sol-gel technique and supercritical $\mathrm{CO}_{2}$ drying [19-25]. However, the manufacturing of cellulose nanocomposites with native cellulose (cellulose I) crystallinity is still a challenge due to inhomogeneous dispersion in hydrophobic polymer matrix as well as thermal instability of cellulose nanofillers above $200^{\circ} \mathrm{C}$. The majority of thermoplastics exhibit melting points between 160 and $220^{\circ} \mathrm{C}$,

$\overline{{ }^{*} \text { Corresponding author, e-mail: dskim@,cbnu.ac.kr }}$ (C) BME-PT 
which are in the range of thermal decomposition of wood [18].

Cellulose with regenerated crystallinity (cellulose II) can be prepared as hydrogels by dissolution and coagulation. Recently, many researchers have reported the use of aqueous alkali hydroxide-urea solution for dissolution and gel preparation of cellulose nanofillers. The resulting three-dimensional cellulose gel was reported to be highly porous of nanometer order, and have remarkable mechanical strength and high light transmittance [26-28]. The usefulness of nanoporous cellulose gels (NCGs) as nanomaterials can be seen through aerogel preparation and in-situ synthesis of metallic, inorganic and conductive nanoparticles $[29,30]$. It can also be used as a substrate for tough, foldable and transparent composite films. Recently, Li and coworker [31,32] studied the reinforcement effect of three-dimensionally nanoporous cellulose gels in poly-( $\varepsilon$-caprolactone) (PCL) and poly (L-lactide-co-caprolactone) bionanocomposites. They reported that the interconnected nanofibrillar network structure of the NCG were finely distributed and preserved well in PCL and Poly (L-lactide-co-caprolactone) matrix resulted in remarkable improvement in tensile storage modulus of the nanocomposites above glass transition and melting temperatures of the polymer matrix. Similar observations have been made by Shi et al. [33] for poly-(methyl methacrylate-co-butyl methacrylate)/NCG and poly-(methyl methacrylateco-butyl acrylate)/NCG nanocomposites. Pinto et al. [34] fabricated flexible organic light emitting diodes from bacterial cellulose/polyurethane membrane nanocomposites. In the present study, an attempt has been made to prepare tough, foldable and transparent poly(styrene-co-butyl acrylate)/NCG [P (St/BA)/NCG] nanocomposites film. The effect of NCG contents as well as styrene/butyl acrylate ratio (St/BA) on the physico-mechanical, thermal and water resistance properties of $\mathrm{P}(\mathrm{St} / \mathrm{BA}) / \mathrm{NCG}$ nanocomposites have been studied in detail. The prepared nanocomposites will have promising applications in flexible display, packaging and many others.

\section{Experimental}

\subsection{Materials}

Butyl acrylate (BA) was purchased from Junsei Chemicals Co. Ltd., Japan. Styrene (St) was purchased from Daejung Chemical and Metals Co. Ltd, Korea. Benzoyl peroxide (purity 99.98\%) was purchased from Fluka Chemika. $\mathrm{NaOH}$ was purchased from
Shinyo Pure Chemicals Co. Ltd., Japan. Cellulose (cotton linter powder) was purchased from Sigma Aldrich. Epichlorohydrin was purchased from Tokyo Industry Chemicals Co Ltd., Japan. Magnesium sulfate anhydrous $\left(\mathrm{MgSO}_{4}\right)$ was purchased from OCI chemicals Ltd. The monomers, styrene and butyl acrylate, were washed with $10 \% \mathrm{NaOH}$ solution followed by distilled water and dried over $\mathrm{MgSO}_{4}$ prior to polymerization. Benzoyl peroxide was re-crystallized from acetone.

\subsection{Fabrication of nanoporous cellulose gels (NCG)}

$5 \mathrm{~g}$ of cellulose were dispersed into $100 \mathrm{~mL}$ of aqueous $\mathrm{NaOH}(6 \mathrm{wt} \%) /$ urea (12 wt\%) solution with stirring for $5 \mathrm{~min}$ and then was stored in a refrigerator $\left(-10\right.$ to $\left.-12^{\circ} \mathrm{C}\right)$ for $12 \mathrm{~h}$. The frozen solid was allowed to melt and stirred vigorously at room temperature to obtain a colorless transparent cellulose solution. Then, $4 \mathrm{~g}$ of epichlorohydrin $(\mathrm{ECH})$ was added drop wise to the cellulose solution and continued to stirring for $1 \mathrm{~h}$. The cellulose solution was subjected to centrifugation to remove air bubbles. The centrifuged solution was spread on glass mold of different thickness (1, 3 and $5 \mathrm{~mm}$ ) and kept at room temperature $\left(\sim 20^{\circ} \mathrm{C}\right)$ for $12 \mathrm{~h}$ to make gel. Hydrogels as obtained were thoroughly washed with distilled water.

\subsection{Fabrication of dried NCG film}

The NCG hydrogel of $1 \mathrm{~mm}$ thickness was dried at room temperature to obtain a film of thickness $0.1 \mathrm{~mm}$.

\subsection{Fabrication of $\mathrm{P}(\mathrm{St} / \mathrm{BA}) / \mathrm{NCG}$ nanocomposites by in-situ polymerization}

NCG hydrogels of different thickness (1,3 and $5 \mathrm{~mm})$ were compressed under $0.2 \mathrm{MPa}$ at $60^{\circ} \mathrm{C}$ to $0.9 \mathrm{~mm}$ to form hydrogels with different water content, i.e., various porosities. These NCG hydrogels were then solvent exchanged with acetone and impregnated into styrene and butyl acrylate monomer mixture (St/BA, at various ratios) containing $1 \%(\mathrm{w} / \mathrm{v})$ benzoyl peroxide as initiator, at room temperature for $24 \mathrm{~h}$. The gels were then sealed in a glass mold, and heated at $50^{\circ} \mathrm{C}$ for $12 \mathrm{~h}$ to polymerize followed by $80^{\circ} \mathrm{C}$ for $3 \mathrm{~h}$ to remove the residual monomer and solvent.

The volume fraction of NCG in the nanocomposites was determined gravimetrically as an average of 
3 independently prepared samples. First, the water content of the cellulose hydrogels was calculated from swollen and dried state. Then, the imbibed water in weighted hydrogels was solvent exchanged to acetone and finally to monomers containing initiator. After in-situ polymerization, the nanocomposites were weighted [33]. The densities of cellulose, PS and PBA are 1.62, 1.04 and $1.08 \mathrm{~g} / \mathrm{cm}^{3}$. So, the density of poly-(styrene-co-butyl acrylate) [P (St/BA)] is about $1.06 \mathrm{~g} / \mathrm{cm}^{3}$. The error in the measurements was limited to $\pm 2 \%$.

\subsection{Morphological study}

Morphological studies of the NCG and nanocomposites were carried out on a field emission scanning electron microscope (FE-SEM), LEO-1530FE microscope (Carl Zeiss NTS GmbH, Germany), operating at $30 \mathrm{kV}$. For this, NCGs were cryofractured from liquid nitrogen followed by freeze drying. Samples of organogel (NCG solvent exchange with acetone) and nanocomposities were also cryogenically fractured and vacuum dried. The fracture surface of the hydrogel was sputtered with gold, and subsequently examined.

\subsection{Nuclear magnetic resonance (NMR) spectroscopy}

${ }^{1} \mathrm{H}$ NMR spectra of the $\mathrm{P}$ (St/BA)/NCG nanocomposites were recorded at $500 \mathrm{MHz}$ on a Bruker AVANCE $500 \mathrm{MHz}$ using $\mathrm{CDCl}_{3}$ as solvent. For NMR study, we dissolved the poly-(styrene-co-butyl acrylate) copolymer in $\mathrm{CDCl}_{3}$ and removed the insoluble cellulose part by filtration. The copolymer compositions (St/BA ratios) in nanocomposite films were calculated from the relative intensities of phenyl proton (of St) resonance at 6.4-7.8 ppm, and signals from $-\mathrm{OCH}_{2}-$ proton (of BA) resonance at 3.3$4.5 \mathrm{ppm}$

\subsection{Fourier transform infrared (FT-IR) spectroscopy}

FT-IR spectra were recorded at ambient temperature on a FTIR spectrometer (Nicolet 5700 FTIR Spectrometer, MA) in the wavelength range from 4000 to $400 \mathrm{~cm}^{-1}$ with a $2 \mathrm{~cm}^{-1}$ resolution and an accumulation of 32 scans.

\subsection{Mechanical properties}

The tensile testing of the nanocomposite was carried out in a universal testing machine (LR-30K, Lloyd,
Hampshire, UK) with a cross-head speed of $2 \mathrm{~mm} / \mathrm{min}$ at room temperature $\left(25 \pm 2{ }^{\circ} \mathrm{C}\right)$. The error in the measurements was limited to $\pm 1 \%$.

\subsection{Dynamic mechanical analysis (DMA)}

Dynamic mechanical analysis of the nanocomposites was carried out on a DMA 2980 (TA instruments). The experiment was performed in tension mode at a frequency of $1.0 \mathrm{~Hz}$. The temperature range of the testing was -70 to $+160^{\circ} \mathrm{C}$ with a programmed heating rate of $5^{\circ} \mathrm{C} \mathrm{min}^{-1}$. The error in the measurements was limited to $\pm 1 \%$.

\subsection{Differential scanning calorimetry (DSC)}

Differential scanning calorimetry (DSC) measurements were performed using a DSC Q2000 (TA instruments) thermal analyzer at a heating rate of $10^{\circ} \mathrm{C}$ per minute under a nitrogen atmosphere. The temperature range was -30 to $+100^{\circ} \mathrm{C}$. The error in the measurements was limited to $\pm 2 \%$.

\subsection{Thermogravimetry analysis (TGA)}

Thermogravimetric analyses (TGA) of the nanocomposites were performed on a Discovery TGA (TA instruments) in a nitrogen atmosphere at a heating rate of $10^{\circ} \mathrm{C} / \mathrm{min}$ from 30 to $700^{\circ} \mathrm{C}$. The error in the measurements was limited to $\pm 1 \%$.

\subsection{Water uptake}

Water uptake of the nanocomposites was determined by immersing samples in deionized water at room temperature for $48 \mathrm{~h}$. The sample was vacuum dried at $60^{\circ} \mathrm{C}$ for $24 \mathrm{~h}$, and then the water uptake was determined by measuring the weight of the samples before and after swelling. The error in the measurements was limited to $\pm 2 \%$.

\section{Results and discussion \\ 3.1. Morphologies of NCG and nanocomposites}

Figure $1 \mathrm{a}$ and $1 \mathrm{~b}$ show the SEM images of the surface and cross-section of dried NCG films. The NCG films were formed by a compact 3D network of interconnected cellulose nanofibrils that loosely spaced from each other, providing large pore volume for polymerization. The nanoporous, interconnected nanofibrillar network structure of NCG (Figure 1a and 1b) is preserved well throughout the solvent exchange process with acetone (Figure 1c). The process of solvent exchange with acetone in the never dried 


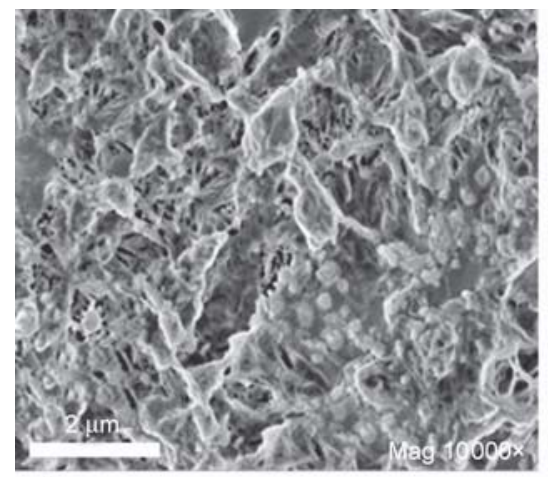

a)

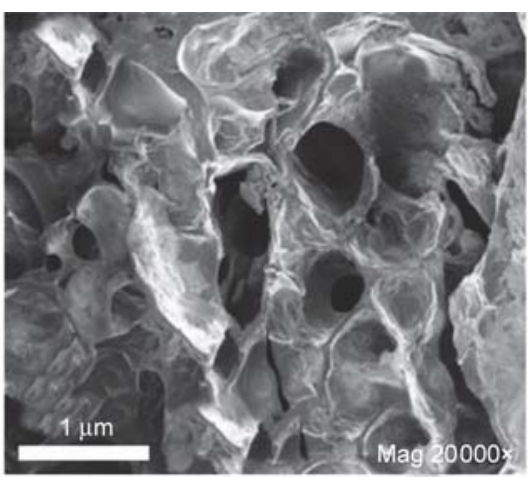

b)

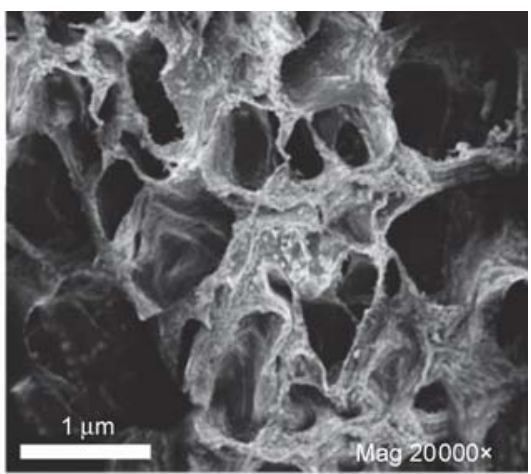

c)

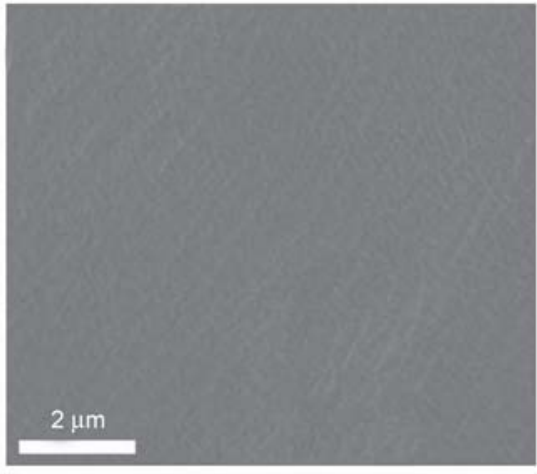

d)

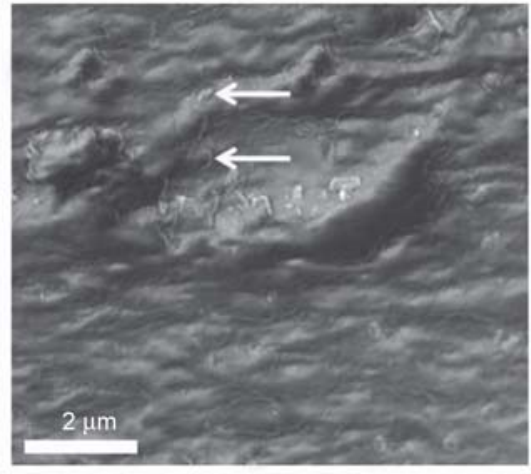

e)

Figure 1. SEM images of (a) the surface of the dried NCG, (b) cross-section of the dried NCG, (c) cross-section of the organogel (NCG solvent exchange with acetone), (d) surface of the P (St/BA)/NCG nanocomposites, (e) crosssection of the $\mathrm{P}(\mathrm{St} / \mathrm{BA}) / \mathrm{NCG}$ nanocomposites

cellulose hydrogel membranes had an important role in the fabrication of nanocomposites film with nanoporous interconnected nanofibrillar network structure. The use of acetone greatly allowed the penetration of monomers mixture ( $\mathrm{St}$ and $\mathrm{BA}$ ) in to the NCGs as it was the common solvent in NCG and monomers mixture. Figure 1d and 1e show the SEM images of the surface and the cross section of $\mathrm{P}(\mathrm{St} / \mathrm{BA}) / \mathrm{NCG}$ nanocomposites. The 3D network of interconnected cellulose nanofibres on the surface of the $\mathrm{P}(\mathrm{St} / \mathrm{BA}) / \mathrm{NCG}$ nanocomposites completely disappeared after polymerization i.e. NCG films surface were covered with poly-(styrene-co-butyl acrylate) $[\mathrm{P}(\mathrm{St} / \mathrm{BA})]$ after polymerization. It can be seen that the nanoporous, interconnected nanofibrillar network structure of NCGs were finely distributed and preserved well in the nanocomposites after insitu polymerization (thread like shape in Figure 1e). The $\mathrm{P}(\mathrm{St} / \mathrm{BA})$ copolymer did not only cover the surface of the NCGs, but also penetrated through the nonporous network structure of NCG. As a result, the air interstices of NCGs were filled with $\mathrm{P}(\mathrm{St} / \mathrm{BA})$ copolymer (Figure 1e). The resulting nanocomposites films obtained were highly transparent, foldable and self-standing (Figure 2).
The transmittance spectra in the ultraviolet-visible region of the NCG, $\mathrm{P}(\mathrm{St} / \mathrm{BA})$ copolymer and $\mathrm{P}(\mathrm{St} / \mathrm{BA}) / \mathrm{NCG}$ nanocomposites film are shown in Figure 2c. As expected, NCG displayed high transparency in UV-vis region with transmittance values of $66 \%$ at $400 \mathrm{~nm}$ and $85 \%$ at $800 \mathrm{~nm}$, while $\mathrm{P}(\mathrm{St} / \mathrm{BA})$ copolymer showed transmittance values of $55 \%$ at $400 \mathrm{~nm}$ and $75 \%$ at $800 \mathrm{~nm}$. The $\mathrm{P}(\mathrm{St} / \mathrm{BA}) / \mathrm{NCG}$ nanocomposites showed increase in transparency with a transmittance larger than $72 \%$ at $400 \mathrm{~nm}$ and $81 \%$ at $800 \mathrm{~nm}$. The high transparency of the $\mathrm{P}(\mathrm{St} / \mathrm{BA}) / \mathrm{NCG}$ nanocomposites film is observed due to the overlapping of the optical properties of both the NCG and P(St/BA) copolymer films.

\subsection{FTIR and ${ }^{1} H$ NMR study}

Figure 3 shows the FTIR spectra of the NCG, $\mathrm{P}(\mathrm{St} / \mathrm{BA})$ copolymer and $\mathrm{P}(\mathrm{St} / \mathrm{BA}) / \mathrm{NCG}$ nanocomposite. The FTIR spectra of nanocomposites are superposition to those of $\mathrm{NCG}$ and $\mathrm{P}(\mathrm{St} / \mathrm{BA})$. The strong peak from $\mathrm{CO}$ stretching at $1730 \mathrm{~cm}^{-1}$ and $\mathrm{C}=\mathrm{C}$ aromatic stretching at $1600 \mathrm{~cm}^{-1}$ indicates the presence of $\mathrm{P}(\mathrm{St} / \mathrm{BA})$ copolymer in nanocomposites. The peak from $\mathrm{O}-\mathrm{H}$ stretching of cellulose is broadened and shifted from 3402 to $3436 \mathrm{~cm}^{-1}$ is likely due to 

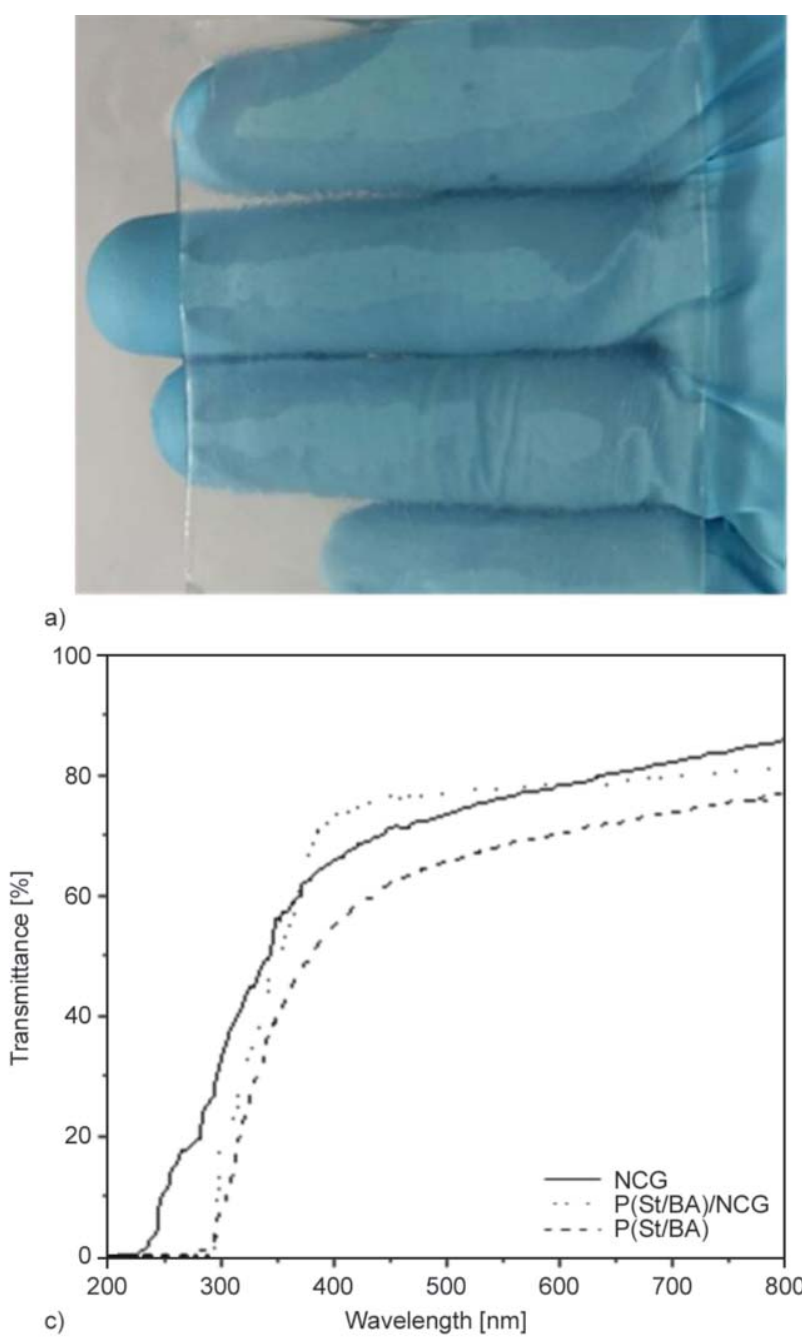

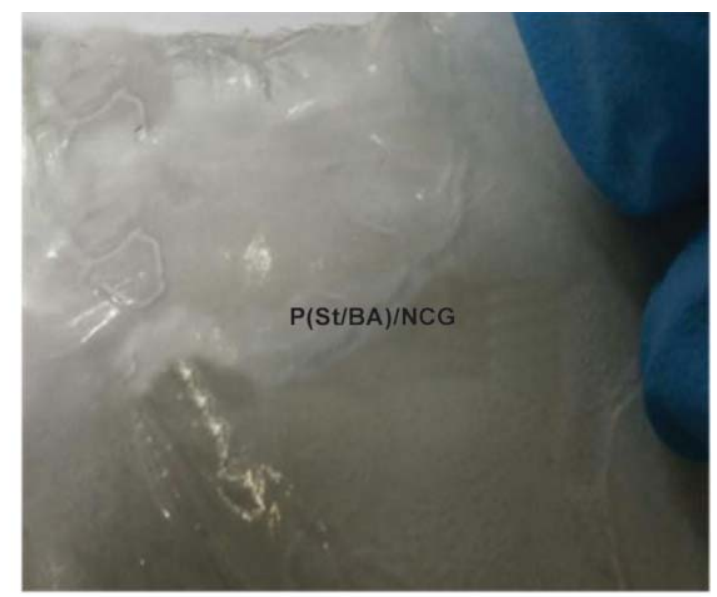

b)

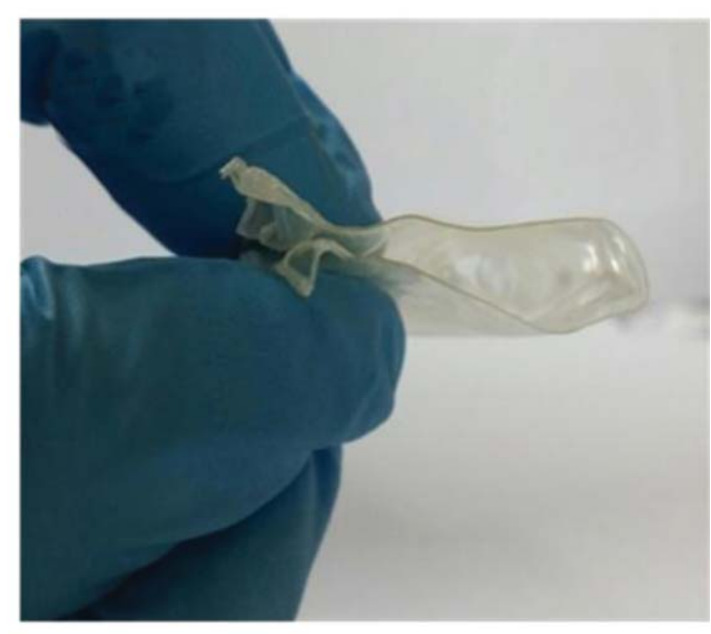

d)

Figure 2. Digital image of (a) NCG, (b) and (d) transparent foldable P(St/BA)/NCG nanocomposite film, (c) transmittance spectra in the ultraviolet-visible wavelength interval of 200-800 nm for the NCG, copolymer and nanocomposites

enhanced hydrogen bonding between NCG hydroxyls and ester group of $\mathrm{P}(\mathrm{St} / \mathrm{BA})$.

The ${ }^{1} \mathrm{H}$ NMR spectra of the nanocomposites films at different St/BA ratios are depicted in Figure 4. The

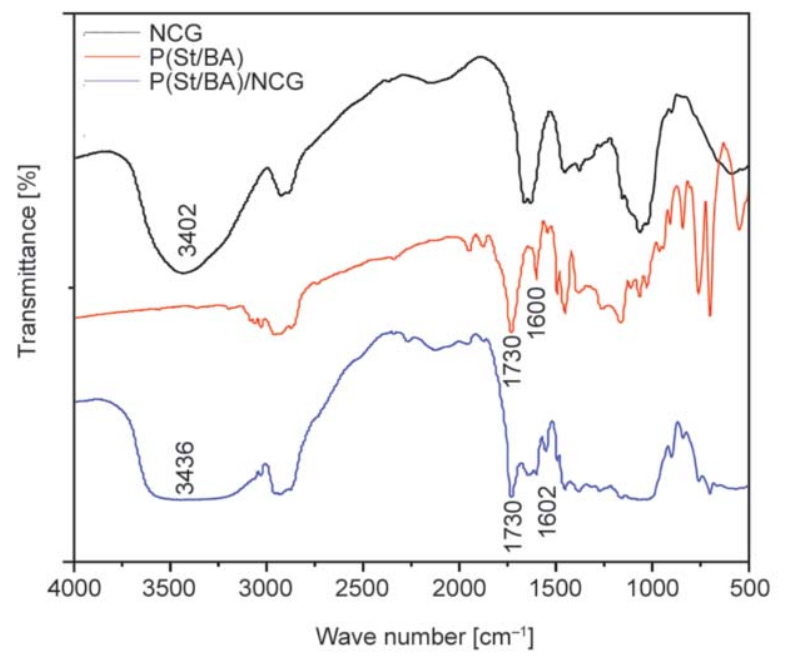

Figure 3. FTIR spectra of NCG, P (St/BA) co-polymer and $\mathrm{P}(\mathrm{St} / \mathrm{BA}) / \mathrm{NCG}$ nanocomposites peak from phenyl proton (of styrene) resonance at 6.4-7.8 ppm, and the peak from $-\mathrm{OCH}_{2}-\left(\mathrm{S}_{2}\right)$ proton (of BA) resonance at 3.3-4.5 ppm confirm the presence of $\mathrm{P}(\mathrm{St} / \mathrm{BA})$ copolymer in nanocomposites. The copolymer compositions (St/BA ratios) in nanocomposite films were calculated from the relative intensities of phenyl $\left(\mathrm{S}_{1}\right)$ and $-\mathrm{OCH}_{2}-\left(\mathrm{S}_{2}\right)$ proton resonance, according to the Equation (1) [34]:

Mole fraction of styrene $=\frac{\frac{S_{1}}{5}}{\frac{S_{1}}{5}+\frac{S_{2}}{2}}$

The NCG contents as well as mole fraction of St and $\mathrm{BA}$ in $\mathrm{P}(\mathrm{St} / \mathrm{BA}) / \mathrm{NCG}$ nanocomposites are summarized in Table 1. NCG contents in nanocomposites were varied by changing the water content in starting NCG hydrogel by compression dewatering before solvent exchange with acetone. After in-situ polymerization, the resulting nanocomposites have volume fraction of NCGs ranging from 16 to $44 \%$. 


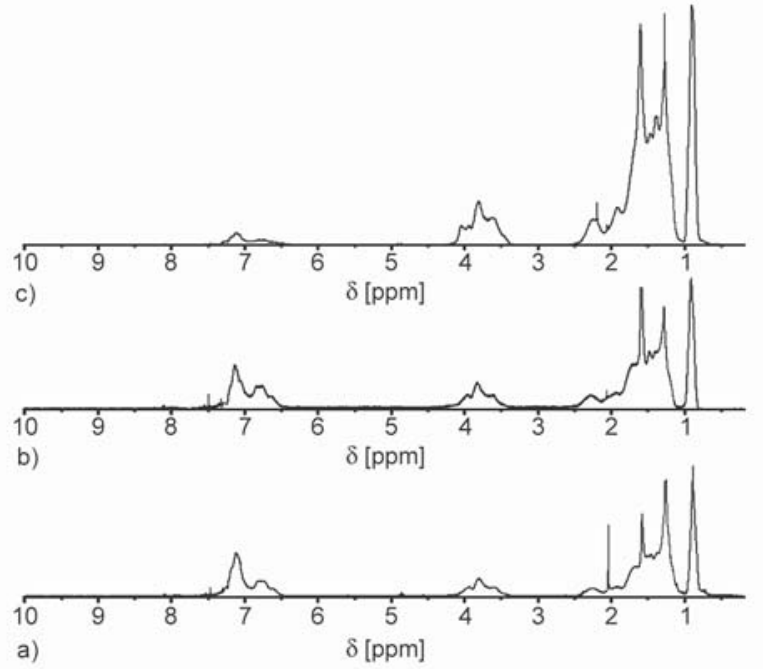

Figure 4. NMR spectra of $\mathrm{P}(\mathrm{St} / \mathrm{BA}) / \mathrm{NCG}$ nanocomposites at various monomer $(\mathrm{St} / \mathrm{BA})$ ratios $(\mathrm{a}) \mathrm{St} / \mathrm{BA}=$ 7/3, (b) St/BA = 1/1, (c) St/BA = 3/7

\subsection{Mechanical properties}

The typical stress strain curves for nanocomposites at various $\mathrm{St} / \mathrm{BA}$ ratios and NCG contents are depicted in Figure 5. The neat $\mathrm{P}(\mathrm{St} / \mathrm{BA})$ are in rubbery state regardless $\mathrm{St} / \mathrm{BA}$ ratios, and undergoes large deformation before break, while all nanocomposites exhibit an elastic nonlinear behavior. Table 2 summarizes the tensile strength, Young modulus and elongation at break of $\mathrm{P}(\mathrm{St} / \mathrm{BA}) / \mathrm{NCG}$ nanocomposites for various St/BA ratio and NCG contents. As expected, the tensile strength and Young's modulus of the nanocomposites increased significantly with increasing NCG contents. However, the elongation at break was remarkably reduced for all nanocomposites. For St/BA (monomer ratio) 7:3, tensile strength
(3.1 MPa) and Young's modulus (567 MPa) for neat $\mathrm{P}(\mathrm{St} / \mathrm{BA})$ increased to 56 and $2195 \mathrm{MPa}$ for $\mathrm{P}(\mathrm{St} / \mathrm{BA}) /$ NCG nanocomposites containing 44\% v/v NCG, while elongation at break reduced to $18 \%$. For St/BA (monomer ratio) $1: 1$, tensile strength $(0.2 \mathrm{MPa})$ and Young's modulus $(0 \mathrm{MPa})$ for neat $\mathrm{P}(\mathrm{St} / \mathrm{BA})$ increased to 44 and $1387 \mathrm{MPa}$ respectively, for $\mathrm{P}(\mathrm{St} / \mathrm{BA}) / \mathrm{NCG}$ nanocomposites containing $44 \% \mathrm{v} / \mathrm{v}$ NCG, while elongation at break reduced to $30 \%$. For St/BA (monomer ratio) $3: 7$, tensile strength $(0.1 \mathrm{MPa})$ and Young's modulus $(0 \mathrm{MPa})$ for neat $\mathrm{P}(\mathrm{St} / \mathrm{BA})$ increased to 39.6 and $1172 \mathrm{MPa}$ respectively, for $\mathrm{P}(\mathrm{St} / \mathrm{BA}) / \mathrm{NCG}$ nanocomposites containing $44 \% \mathrm{v} / \mathrm{v}$ NCG, while elongation at break reduced to $48 \%$. Figure 6 show the tensile strength and Young's modulus versus NCG contents $[\% \mathrm{v} / \mathrm{v}]$ of the $\mathrm{P}(\mathrm{St} / \mathrm{BA})(3 / 7) / \mathrm{NCG}$ nanocomposites for various $\mathrm{St} / \mathrm{BA}$ ratio. The initial sharp rise in tensile strength and Young's modulus for $16 \% \mathrm{v} / \mathrm{v}$ NCG is likely due to interconnected nanofibrillar cellulose network present in nanocomposites. The nanofibrillar cellulose network present in nanocomposites provides extraordinary reinforcement to the $\mathrm{P}(\mathrm{St} / \mathrm{BA})$ matrix [31].

\subsection{Thermal analysis}

DMA is used to measure the thermomechanical properties of the nanocomposites. Figure 7 shows the variation of storage modulus and loss tangent $(\tan \delta)$ with temperature for $\mathrm{P}(\mathrm{St} / \mathrm{BA})(3 / 7) / \mathrm{NCG}$ nanocomposite with different volume fraction of $\mathrm{NCG}$, in which the ' $\alpha$ ' relaxation process of chain segment is sometimes referred to as glass transition temperature $\left(T_{\mathrm{g}}\right)$. From the maximum loss in tangent, $\mathrm{P}(\mathrm{St} / \mathrm{BA})$

Table 1. Sample designations, NCG contents as well as mole fraction of St and BA in P(St/BA)/NCG nanocomposites

\begin{tabular}{|l|c|c|c|c|}
\hline \multicolumn{1}{|c|}{ Sample ID } & $\begin{array}{c}\text { St/BA } \\
\text { (monomer ratio) }\end{array}$ & $\begin{array}{c}\text { Volume of NCG } \\
\text { in nanocomposites } \\
{[\% \text { v/v] }}\end{array}$ & $\begin{array}{c}\text { Mole percentage } \\
\text { of styrene } \\
\text { in nanocomposites }\end{array}$ & $\begin{array}{c}\text { Mole percentage } \\
\text { of butyl acrylate } \\
\text { in nanocomposites }\end{array}$ \\
\hline $\mathrm{NCG}$ & - & 100 & - & - \\
\hline $\mathrm{P}(\mathrm{St} / \mathrm{BA})(7 / 3)$ & $7 / 3$ & - & 74 & 26 \\
\hline $\mathrm{P}(\mathrm{St} / \mathrm{BA})(7 / 3) / \mathrm{NCG}-16 \%$ & $7 / 3$ & 16 & 77 & 23 \\
\hline $\mathrm{P}(\mathrm{St} / \mathrm{BA})(7 / 3) / \mathrm{NCG}-28 \%$ & $7 / 3$ & 28 & 77 & 23 \\
\hline $\mathrm{P}(\mathrm{St} / \mathrm{BA})(7 / 3) / \mathrm{NCG}-44 \%$ & $7 / 3$ & 44 & 77 & 45 \\
\hline $\mathrm{P}(\mathrm{St} / \mathrm{BA})(1 / 1)$ & $1 / 1$ & - & 55 & 46 \\
\hline $\mathrm{P}(\mathrm{St} / \mathrm{BA})(1 / 1) / \mathrm{NCG}-16 \%$ & $1 / 1$ & 16 & 54 & 46 \\
\hline $\mathrm{P}(\mathrm{St} / \mathrm{BA})(1 / 1) / \mathrm{NCG}-28 \%$ & $1 / 1$ & 28 & 54 & 65 \\
\hline $\mathrm{P}(\mathrm{St} / \mathrm{BA})(1 / 1) / \mathrm{NCG}-44 \%$ & $1 / 1$ & 44 & 54 & 67 \\
\hline $\mathrm{P}(\mathrm{St} / \mathrm{BA})(3 / 7)$ & $3 / 7$ & - & 35 & 67 \\
\hline $\mathrm{P}(\mathrm{St} / \mathrm{BA})(3 / 7) / \mathrm{NCG}-16 \%$ & $3 / 7$ & 16 & 33 & 67 \\
\hline $\mathrm{P}(\mathrm{St} / \mathrm{BA})(3 / 7) / \mathrm{NCG}-28 \%$ & $3 / 7$ & 28 & 33 & 33 \\
\hline $\mathrm{P}(\mathrm{St} / \mathrm{BA})(3 / 7) / \mathrm{NCG}-44 \%$ & $3 / 7$ & 44 & & \\
\hline
\end{tabular}



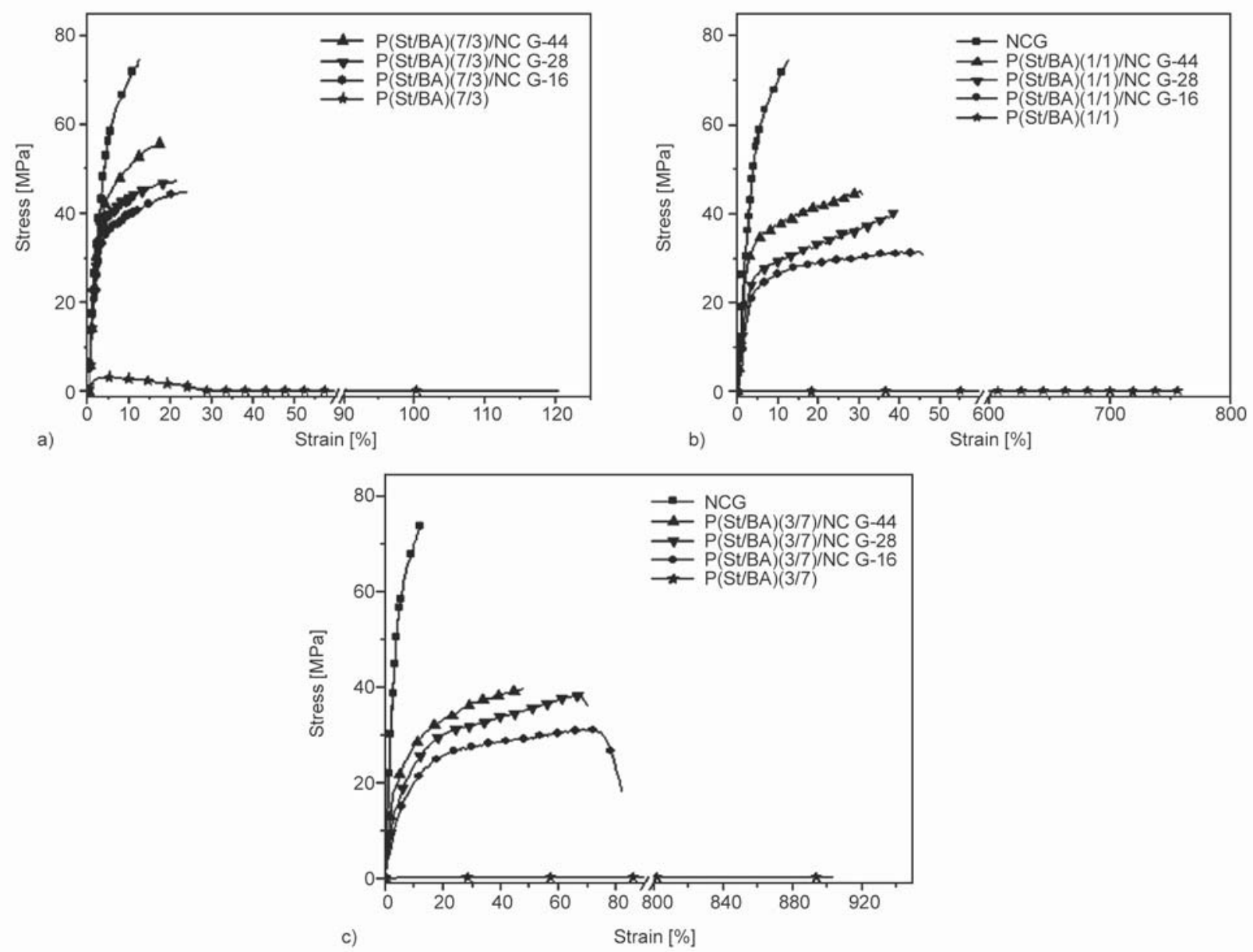

Figure 5. Stress-strain curves for (a) $\mathrm{P}(\mathrm{St} / \mathrm{BA})(7 / 3) / \mathrm{NCG}$, (b) $\mathrm{P}(\mathrm{St} / \mathrm{BA})(1 / 1) / \mathrm{NCG}$, (c) $\mathrm{P}(\mathrm{St} / \mathrm{BA})(3 / 7) / \mathrm{NCG}$ nanocomposites

copolymer is in glassy state below $-12^{\circ} \mathrm{C}$ show rather high stiffness $\left(E^{\prime}\right)$, while above $-12{ }^{\circ} \mathrm{C} \mathrm{P}(\mathrm{St} / \mathrm{BA})$ copolymer show typical rubbery behavior and cause sudden drop of $E^{\prime}$ to null at $40^{\circ} \mathrm{C}$. The introduction

Table 2. Tensile strength, Young's modulus and elongation at break of $\mathrm{P}(\mathrm{St} / \mathrm{BA}) / \mathrm{NCG}$ nanocomposites for various $\mathrm{St} / \mathrm{BA}$ ratio and $\mathrm{NCG}$ contents

\begin{tabular}{|l|c|c|c|}
\hline \multicolumn{1}{|c|}{ Sample ID } & $\begin{array}{c}\text { Tensile } \\
\text { strength } \\
{[\mathbf{M P a}]}\end{array}$ & $\begin{array}{c}\text { Young's } \\
\text { modulus } \\
\text { [MPa] }\end{array}$ & $\begin{array}{c}\text { EB } \\
{[\%]}\end{array}$ \\
\hline $\mathrm{NCG}$ & 74.50 & 2850 & 12.5 \\
\hline $\mathrm{P}(\mathrm{St} / \mathrm{BA})(7 / 3)$ & 3.08 & 567 & 58.0 \\
\hline $\mathrm{P}(\mathrm{St} / \mathrm{BA})(7 / 3) / \mathrm{NCG}-16 \%$ & 44.78 & 1592 & 24.0 \\
\hline $\mathrm{P}(\mathrm{St} / \mathrm{BA})(7 / 3) / \mathrm{NCG}-28 \%$ & 47.20 & 1776 & 21.2 \\
\hline $\mathrm{P}(\mathrm{St} / \mathrm{BA})(7 / 3) / \mathrm{NCG}-44 \%$ & 56.00 & 2195 & 18.0 \\
\hline $\mathrm{P}(\mathrm{St} / \mathrm{BA})(1 / 1)$ & 0.20 & - & 385.0 \\
\hline $\mathrm{P}(\mathrm{St} / \mathrm{BA})(1 / 1) / \mathrm{NCG}-16 \%$ & 30.90 & 1016 & 45.8 \\
\hline $\mathrm{P}(\mathrm{St} / \mathrm{BA})(1 / 1) / \mathrm{NCG}-28 \%$ & 40.10 & 1246 & 38.5 \\
\hline $\mathrm{P}(\mathrm{St} / \mathrm{BA})(1 / 1) / \mathrm{NCG}-44 \%$ & 44.50 & 1387 & 30.2 \\
\hline $\mathrm{P}(\mathrm{St} / \mathrm{BA})(3 / 7)$ & 0.10 & - & 658.0 \\
\hline $\mathrm{P}(\mathrm{St} / \mathrm{BA})(3 / 7) / \mathrm{NCG}-16 \%$ & 31.20 & 850 & 80.9 \\
\hline $\mathrm{P}(\mathrm{St} / \mathrm{BA})(3 / 7) / \mathrm{NCG}-28 \%$ & 38.30 & 967 & 70.4 \\
\hline $\mathrm{P}(\mathrm{St} / \mathrm{BA})(3 / 7) / \mathrm{NCG}-44 \%$ & 39.60 & 1172 & 47.9 \\
\hline
\end{tabular}

of NCG matrix changes the behavior drastically. The increase in $E^{\prime}$ by NCG is modest at below $T_{\mathrm{g}}$, due to already rather high stiffness of the glassy state. However, the increase in $E^{\prime}$ by NCG is remarkable (significant mechanical reinforcement over $\mathrm{P}(\mathrm{St} / \mathrm{BA})$ copolymer) at above $T_{\mathrm{g}}$, and suppressed the collapse due to softening of $\mathrm{P}(\mathrm{St} / \mathrm{BA})$. For example, at $-25^{\circ} \mathrm{C}$, $E^{\prime}$ is increase from $2839 \mathrm{MPa}$ for $\mathrm{P}(\mathrm{St} / \mathrm{BA})(3 / 7)$ to $4003 \mathrm{MPa}$ for $\mathrm{P}(\mathrm{St} / \mathrm{BA})(3 / 7) / \mathrm{NCG}-44$, while at $25^{\circ} \mathrm{C}, E^{\prime}$ is increased by over 3 order of magnitude from $0.36 \mathrm{MPa}$ for $\mathrm{P}(\mathrm{St} / \mathrm{BA})(3 / 7)$ to $362.39 \mathrm{MPa}$ for $\mathrm{P}(\mathrm{St} / \mathrm{BA})(3 / 7) / \mathrm{NCG}-44$ nanocomposites. Recently, Li et al. [31] and Shi et al. [33] also reported similar reinforcement effect of NCG on PCL and P(MMA/ BMA) copolymer. The significant improvement in mechanical reinforcement is due to the interconnected nanofibrillar network structure of NCG as well as strong intermolecular hydrogen bonding between NCG and polymer matrix, as discussed earlier. From $\tan \delta$ peak (Figure $7 \mathrm{~b}$ ), the $T_{\mathrm{g}}$ for $\mathrm{P}(\mathrm{St} / \mathrm{BA})$ is shifted to higher temperature for nanocomposites with increasing NCG contents. Moreover, The intensity of the $\tan \delta$ peak for $\mathrm{P}(\mathrm{St} / \mathrm{BA})$ decreased more 

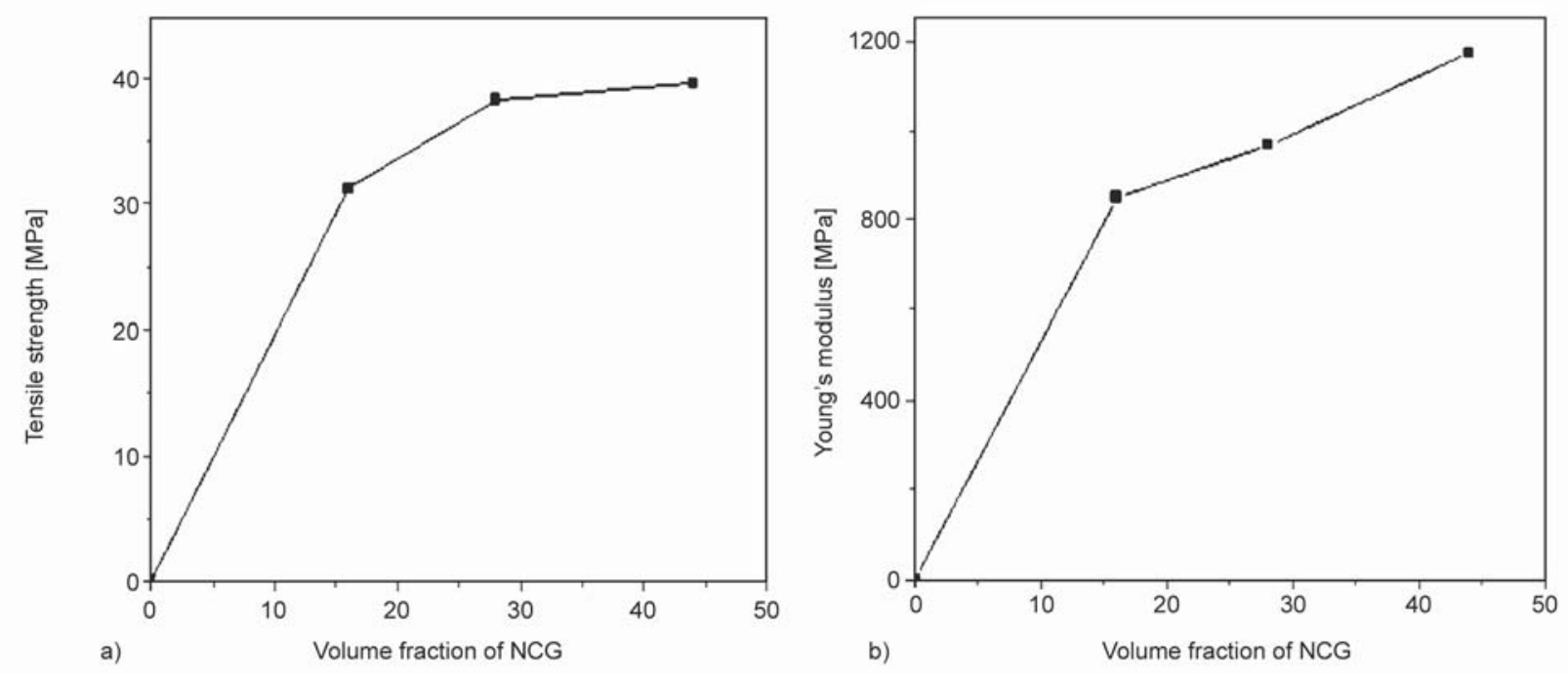

Figure 6. (a) Tensile strength, (b) Young's modulus, as a function of volume fraction of NCG for P(St/BA)(3/7)/NCG nanocomposites
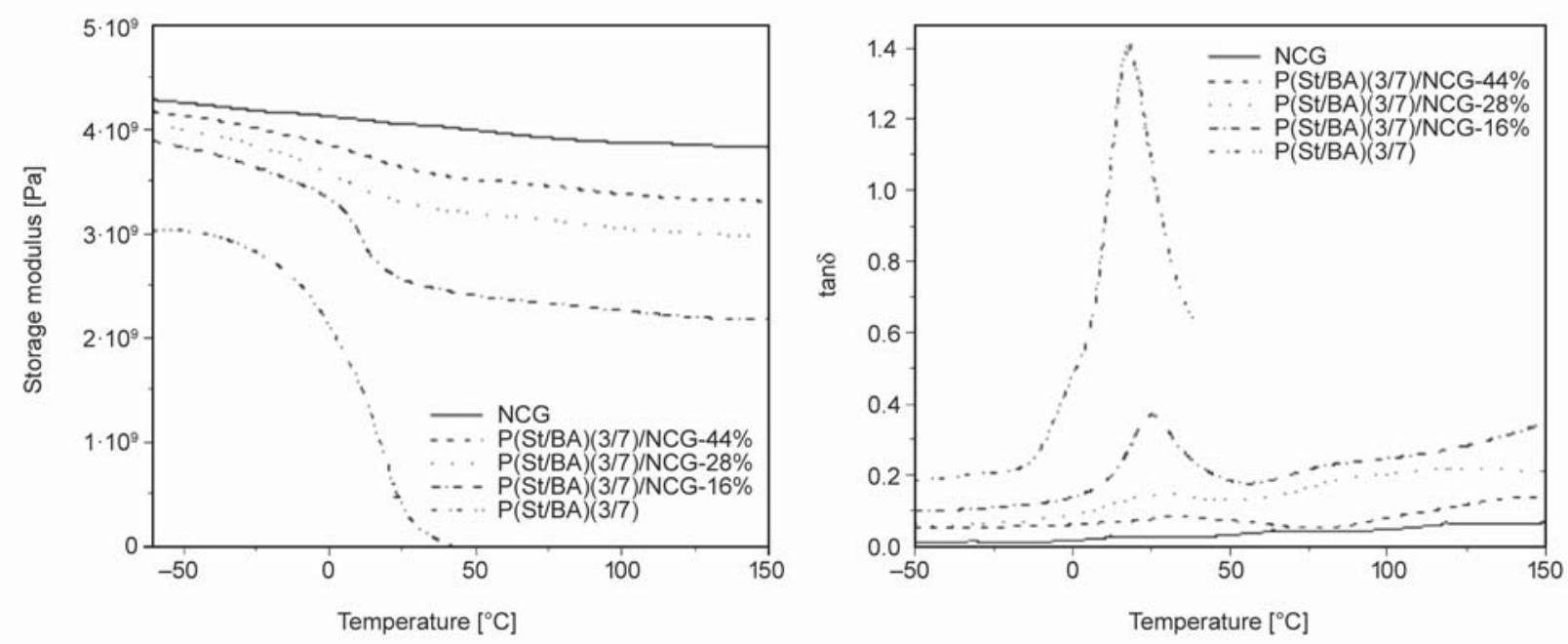

Figure 7. (a) Storage modulus, (b) tan $\delta$, as a function of temperature for $\mathrm{P}(\mathrm{St} / \mathrm{BA})(3 / 7) / \mathrm{NCG}$ nanocomposites

than proportionally to the NCG content of the nanocomposites is likely due to the strong hydrogen

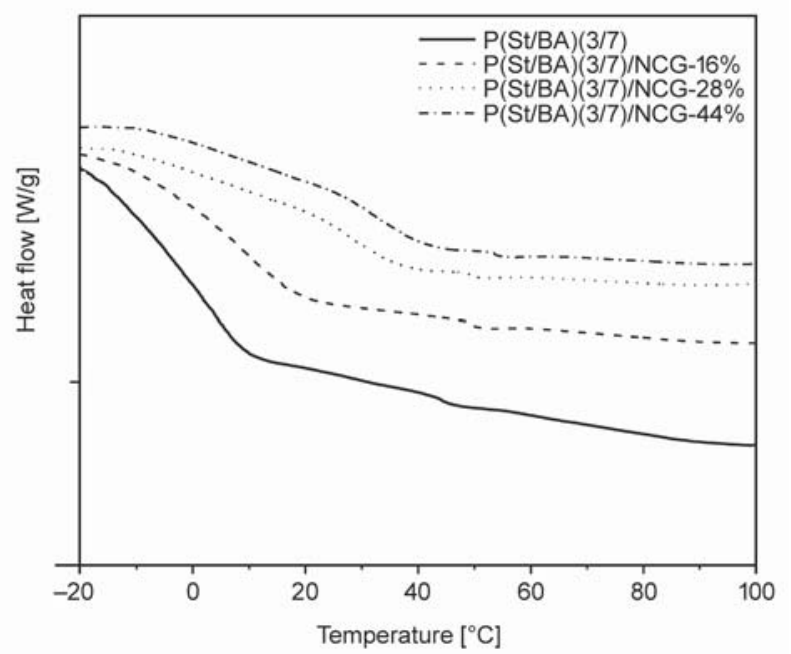

Figure 8. DSC thermograms of $\mathrm{P}(\mathrm{St} / \mathrm{BA})(3 / 7) / \mathrm{NCG}$ nanocomposites bonding between polymer matrix and NCG (as observed from FTIR spectra) as well as strong confinement effects from the NCG network, which leads to pronounced reduction in chain relaxation. The shifting of $T_{\mathrm{g}}$ towards higher temperature for nanocomposites with increasing NCG contents was also observed from DSC analysis (Figure 8).

\subsection{Thermogravimetric analysis}

The thermal degradation behavior of NCG, $\mathrm{P}(\mathrm{St} / \mathrm{BA})$ and $\mathrm{P}(\mathrm{St} / \mathrm{BA})(3 / 7) / \mathrm{NCG}$ nanocomposites are depicted in Figure 9a (TG) and 9b (DTG). It can be seen that $\mathrm{P}(\mathrm{St} / \mathrm{BA})(3 / 7)$ starts to degrade at $146^{\circ} \mathrm{C}$ and completed at around $470^{\circ} \mathrm{C}$. The $T_{\text {onset }}$ (initial decomposition temperature at $5 \mathrm{wt} \%$ loss) and $T_{\max }$ (temperature for maximum decomposition) for $\mathrm{P}(\mathrm{St} / \mathrm{BA})(3 / 7)$ are observed at 218 and $412^{\circ}$, respectively. The $T_{\text {onset }}$ and $T_{\max }$ for NCG are appeared at 
Table 3. Characteristic TG data obtained from the thermal degradation of $\mathrm{P}(\mathrm{St} / \mathrm{BA})(3 / 7) / \mathrm{NCG}$ nanocomposites

\begin{tabular}{|c|c|c|c|}
\hline Sample ID & \multicolumn{2}{|c|}{$\begin{array}{l}T_{\text {onset }} \\
{\left[{ }^{\circ} \mathbf{C}\right]}\end{array}$} & $\begin{array}{l}\Gamma_{\max } \\
\left.{ }^{\circ} \mathrm{C}\right]\end{array}$ \\
\hline NCG & \multicolumn{2}{|c|}{231} & 323 \\
\hline $\mathrm{P}(\mathrm{St} / \mathrm{BA})(3 / 7)$ & \multicolumn{2}{|c|}{218} & 412 \\
\hline & $\begin{array}{c}T_{\text {onset }} \\
{\left[{ }^{\circ} \mathbf{C}\right]}\end{array}$ & $\begin{array}{c}T_{\max 1} \\
{\left[{ }^{\circ} \mathbf{C}\right]}\end{array}$ & $\begin{array}{c}T_{\max 2} \\
{\left[{ }^{\circ} \mathrm{C}\right]}\end{array}$ \\
\hline $\mathrm{P}(\mathrm{St} / \mathrm{BA})(3 / 7) / \mathrm{NCG}-16 \%$ & 235 & 335 & 419 \\
\hline $\mathrm{P}(\mathrm{St} / \mathrm{BA})(3 / 7) / \mathrm{NCG}-28 \%$ & 237 & 335 & 436 \\
\hline $\mathrm{P}(\mathrm{St} / \mathrm{BA})(3 / 7) / \mathrm{NCG}-44 \%$ & 238 & 339 & 449 \\
\hline
\end{tabular}

231 and $323^{\circ}$, respectively. The $\mathrm{P}(\mathrm{St} / \mathrm{BA})(3 / 7) / \mathrm{NCG}$ nanocomposites undergo two step degradation process. The first step is for degradation of NCG and the second step is for degradation of $\mathrm{P}(\mathrm{St} / \mathrm{BA})$. Table 3 summarizes the $T_{\text {onset }}$ and $T_{\max }$ for NCG, P(St/BA) and $\mathrm{P}(\mathrm{St} / \mathrm{BA})(3 / 7) / \mathrm{NCG}$ nanocomposites. The $T_{\text {onset }}$ and $T_{\max }$ for nanocomposites are higher than those of $\mathrm{NCG}$ and $\mathrm{P}(\mathrm{St} / \mathrm{BA})$ suggesting mutual stabilization of NCG and $\mathrm{P}(\mathrm{St} / \mathrm{BA})$ in nanocomposites. The thermal degradation temperature ( $T_{\text {onset }}$ and $\left.T_{\max }\right)$ of nanocomposites are increased with increasing NCG contents. The improvement in thermal stability of the nanocomposites can be attributed to the nanoscopic-confinement effect of NCG [35].

\subsection{Water uptake}

The water uptake for NCG, $\mathrm{P}(\mathrm{St} / \mathrm{BA})$ copolymer and nanocomposites are illustrated in Figure 10a. Dried samples were immersed into deionized water for 30 days to achieve the equilibrium swelling. NCG is highly hydrophilic and have much higher water uptake, while $\mathrm{P}(\mathrm{St} / \mathrm{BA})$ is hydrophobic and has water uptake values of $(\sim 0.4 \% \mathrm{w} / \mathrm{w})$ with minor variations within 30 days. As expected, hybridization of $\mathrm{NCG}$ with $\mathrm{P}(\mathrm{St} / \mathrm{BA})$ reduced its water uptake. The nanocomposites showed significant water resistance over NCG. Figure 10b shows the effect of NCG content on water uptake of nanocomposites after $48 \mathrm{~h}$ immersion in deionized water. It can be seen that water uptake of nanocomposites is nearly proportional to the NCG content on nanocomposites, is likely due to interconnected network structure of hydrophilic NCG.

\section{Conclusions}

The $\mathrm{P}(\mathrm{St} / \mathrm{BA}) / \mathrm{NCG}$ nanocomposite were prepared by in-situ polymerization of St/BA monomer mixtures in nanoporous regenerated cellulose gels from aqueous alkali hydroxide-urea solution. The NCG content in nanocomposite was controlled by changing water content of starting hydrogel by squeezing it out under slow compression. The prepared nanocomposites were foldable and exhibited excellent transparency (up to $82 \%$ ) in the visible region. The interconnected nanofibrillar network structure of NCG was finely distributed and preserved well in the nanocomposites leading to a remarkable improvement in tensile strength, Young's modulus, tensile storage modulus and thermal stability of the nanocomposites. Moreover, the nanocomposites showed significant water resistance over NCG. The prepared flexible transparent nanocomposite film will have great promising applications in packing, flexible display and many others.
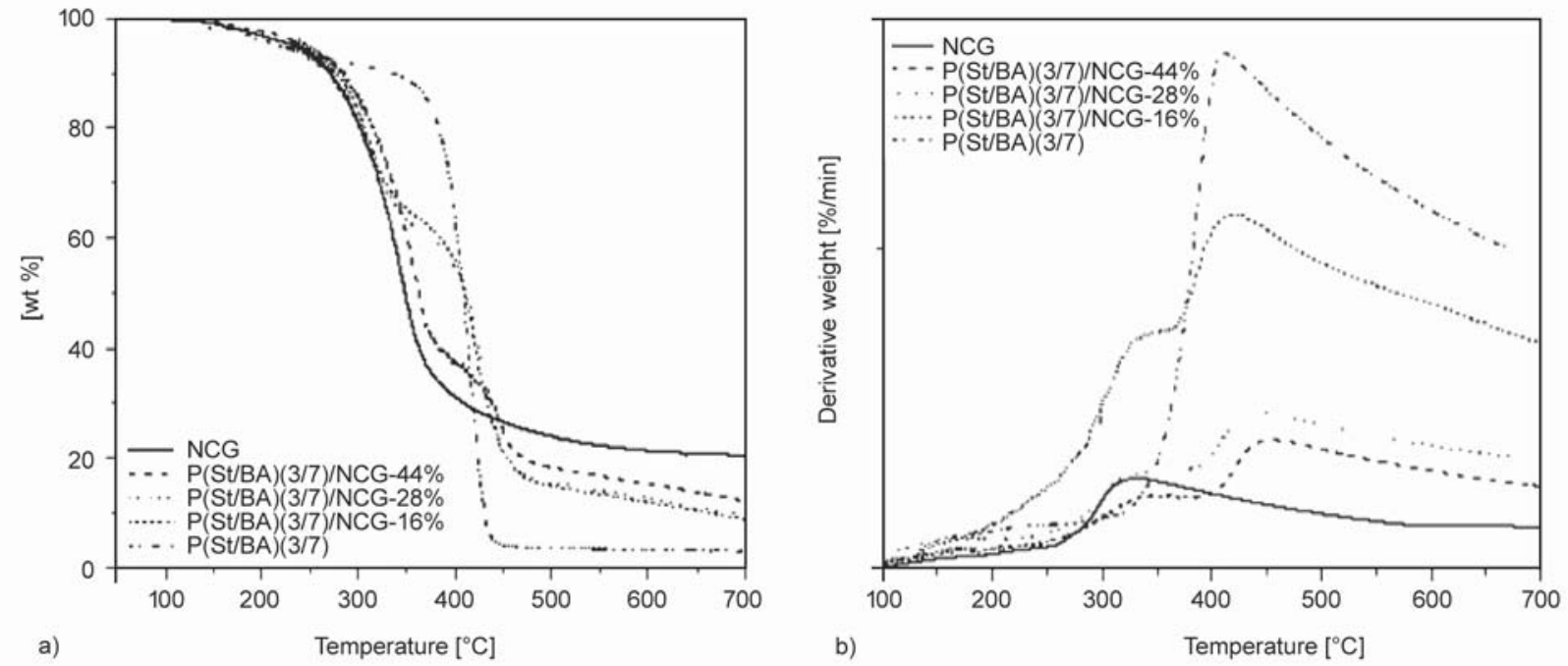

Figure 9. (a) TG, (b) DTG of $\mathrm{NCG}, \mathrm{P}(\mathrm{St} / \mathrm{BA})$ and $\mathrm{P}(\mathrm{St} / \mathrm{BA})(3 / 7) / \mathrm{NCG}$ nanocomposites 

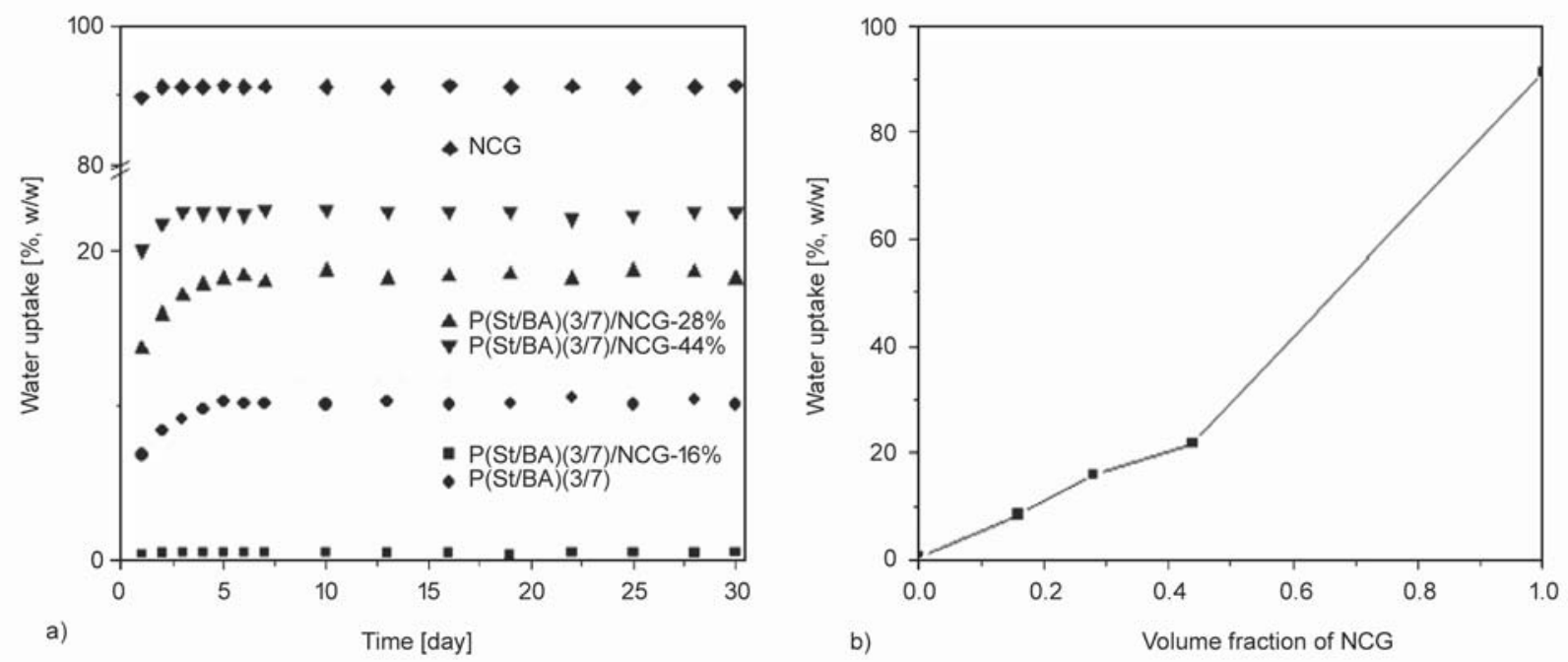

Figure 10. (a) Water uptake of the NCG, $\mathrm{P}(\mathrm{St} / \mathrm{BA})$ and $\mathrm{P}(\mathrm{St} / \mathrm{BA})(3 / 7) / \mathrm{NCG}$ nanocomposites, (b) water uptake as a function of volume fraction of $\mathrm{NCG}$ for $\mathrm{P}(\mathrm{St} / \mathrm{BA})(3 / 7) / \mathrm{NCG}$ nanocomposites

\section{References}

[1] Singha A. S., Rana R. K.: Natural fiber reinforced polystyrene composites: Effect of fiber loading, fiber dimensions and surface modification on mechanical properties. Materials and Design, 41, 289-297 (2012). https://doi.org/10.1016/j.matdes.2012.05.001

[2] Tanaka S., Iwata T., Iji M.: Solvent effects on heterogeneous synthesis of cardanol-bonded cellulose thermoplastics. Polymer, 99, 307-314 (2016). https://doi.org/10.1016/j.polymer.2016.07.024

[3] Ott M. W., Herbert H., Graf M., Biesalski M.: Cellulose-graft-polystyrene bottle-brush copolymers by homogeneous RAFT polymerization of soluble cellulose macro-CTAs and 'CTA-shuttled' R-group approach. Polymer, 98, 505-515 (2016).

https://doi.org/10.1016/j.polymer.2016.05.006

[4] Dikobe D. G., Luyt A. S.: Morphology and properties of polypropylene/ethylene vinyl acetate copolymer/wood powder blend composites. Express Polymer Letters, 3, 190-199 (2009).

https://doi.org/10.3144/expresspolymlett.2009.24

[5] Xu Y., Kawata S., Hosoi K., Kawai T., Kuroda S.: Thermomechanical properties of the silanized-kenaf/polystyrene composites. Express Polymer Letters, 3, 657-664 (2009).

https://doi.org/10.3144/expresspolymlett.2009.82

[6] Reddy K., Zhang J., Zhang J., Rajulu A. V.: Preparation and properties of self-reinforced cellulose composite films from agave microfibrils using an ionic liquid. Carbohydrate Polymers, 114, 537-545 (2014).

https://doi.org/10.1016/j.carbpol.2014.08.054

[7] Dikobe D. G., Luyt A. S.: Comparative study of the morphology and properties of PP/LLDPE/wood powder and MAPP/LLDPE/wood powder polymer blend composites. Express Polymer Letters, 4, 729-741 (2010). https://doi.org/10.3144/expresspolymlett.2010.88
[8] Merlini C., Soldi V., Barra G. M. O.: Influence of fiber surface treatment and length on physico-chemical properties of short random banana fiber-reinforced castor oil polyurethane composites. Polymer Testing, 30, 833840 (2011).

https://doi.org/10.1016/j.polymertesting.2011.08.008

[9] Keledi G., Sudár A., Burgstaller Ch., Renner K., Móczó J., Pukánszky B.: Tensile and impact properties of threecomponent PP/wood/elastomer composites. Express Polymer Letters, 6, 224-236 (2012).

https://doi.org/10.3144/expresspolymlett.2012.25

[10] Sudár A., Burgstaller C., Renner K., Móczó J., Pukánszky B.: Wood fiber reinforced multicomponent, multiphase PP composites: structure, properties, failure mechanism. Composites Science and Technology, 103, 106$112(2014)$. https://doi.org/10.1016/j.compscitech.2014.08.018

[11] John M. J., Anandjiwala R. D.: Chemical modification of flax reinforced polypropylene composites. Composites Part A: Applied Science and Manufacturing, 40, 442-448 (2009).

https://doi.org/10.1016/j.compositesa.2009.01.007

[12] Ishak M. R., Sapuan S. M., Leman Z., Rahman M. Z. A., Anwar U. M. K., Siregar J. P.: Sugar palm (Arenga pinnata): Its fibres, polymers and composites. Carbohydrate Polymers, 91, 699-710 (2013). https://doi.org/10.1016/j.carbpol.2012.07.073

[13] Iyer K. A., Flores A. M., Torkelson J. M.: Comparison of polyolefin biocomposites prepared with waste cardboard, microcrystalline cellulose, and cellulose nanocrystals via solid-state shear pulverization. Polymer, 75, 78-87 (2015). https://doi.org/10.1016/j.polymer.2015.08.029

[14] Liu X., Zhang T., Pang K., Duan Y., Zhang J.: Graphene oxide/cellulose composite films with enhanced UVshielding and mechanical properties prepared in $\mathrm{NaOH} /$ urea aqueous solution. RSC Advances, 6, 73358-73364 (2016).

https://doi.org/10.1039/C6RA16535D 
[15] Yang W., Dominici F., Fortunati E., Kenny J. M., Puglia D.: Melt free radical grafting of glycidyl methacrylate (GMA) onto fully biodegradable poly(lactic) acid films: Effect of cellulose nanocrystals and a masterbatch process. RSC Advances, 5, 32350-32357 (2015). https://doi.org/10.1039/C5RA00894H

[16] Dhar P., Bhasney S. M., Kumar A., Katiyar V.: Acid functionalized cellulose nanocrystals and its effect on mechanical, thermal, crystallization and surfaces properties of poly (lactic acid) bionanocomposites films: A comprehensive study. Polymer, 101, 75-92 (2016). https://doi.org/10.1016/j.polymer.2016.08.028

[17] Miao X., Tian F., Lin J., Li H., Li X., Bian F., Zhang X.: Tuning the mechanical properties of cellulose nanofibrils reinforced polyvinyl alcohol composites via altering the cellulose polymorphs. RSC Advances, 6, 8335683365 (2016).

https://doi.org/10.1039/C6RA14517E

[18] Huan S., Bai L., Cheng W., Han G.: Manufacture of electrospun all-aqueous poly(vinyl alcohol)/cellulose nanocrystal composite nanofibrous mats with enhanced properties through controlling fibers arrangement and microstructure. Polymer, 92, 25-35 (2016). https://doi.org/10.1016/j.polymer.2016.03.082

[19] Wang Y., Yeh F-C., Lai S-M., Chan H-C., Shen H-F.: Effectiveness of functionalized polyolefins as compatibilizers for polyethylene/wood flour composites. Polymer Engineering and Science, 43, 933-945 (2003). https://doi.org/10.1002/pen.10077

[20] Lai S-M., Yeh F-C., Wang Y., Chan H-C., Shen H-F.: Comparative study of maleated polyolefins as compatibilizers for polyethylene/wood flour composites. Journal of Applied Polymer Science, 87, 487-496 (2003). https://doi.org/10.1002/app.11419

[21] Lu J. Z., Wu Q., Negulescu I. I.: Wood-fiber/high-density-polyethylene composites: Coupling agent performance. Journal of Applied Polymer Science, 96, 93-102 (2005). https://doi.org/10.1002/app.21410

[22] Mirmehdi S. M., Zeinaly F., Dabbagh F.: Date palm wood flour as filler of linear low-density polyethylene. Composites Part B: Engineering, 56, 137-141 (2014). https://doi.org/10.1016/j.compositesb.2013.08.008

[23] Mazzanti V., Mollica F., El Kissi N.: Rheological and mechanical characterization of polypropylene-based wood plastic composites. Polymer Composites, 37, 3460-3473 (2016). https://doi.org/10.1002/pc.23546

[24] Prasad N., Agarwal V. K., Sinha S.: Physico-mechanical properties of coir fiber/LDPE composites: Effect of chemical treatment and compatibilizer. Korean Journal of Chemical Engineering, 32, 2534-2541 (2015). https://doi.org/10.1007/s11814-015-0069-z
[25] Poletto M., Zattera A. J., Santana R. M. C.: Effect of natural oils on the thermal stability and degradation kinetics of recycled polypropylene wood flour composites. Polymer Composites, 35, 1935-1942 (2014). https://doi.org/10.1002/pc.22852

[26] Chang C., Zhang L., Zhou J., Zhang L., Kennedy J. F.: Structure and properties of hydrogels prepared from cellulose in $\mathrm{NaOH} /$ urea aqueous solutions. Carbohydrate Polymers, 82, 122-127 (2010). https://doi.org/10.1016/j.carbpol.2010.04.033

[27] Cai J., Kimura S., Wada M., Kuga S., Zhang L.: Cellulose aerogels from aqueous alkali hydroxide-urea solution. ChemSusChem, 1, 149-154 (2008). https://doi.org/10.1002/cssc.200700039

[28] Chang C., Zhang L.: Cellulose-based hydrogels: Present status and application prospects. Carbohydrate Polymers, 84, 40-53 (2011). https://doi.org/10.1016/j.carbpol.2010.12.023

[29] Cai J., Kimura S., Wada M., Kuga S.: Nanoporous cellulose as metal nanoparticles support. Biomacromolecules, 10, 87-94 (2009). https://doi.org/10.1021/bm800919e

[30] Cai J., Liu S., Feng J., Kimura S., Wada M., Kuga S., Zhang L. N.: Cellulose-silica nanocomposite aerogels by in situ formation of silica in cellulose gel. Angewandte Chemie, 51, 2076-2079 (2012). https://doi.org/10.1002/anie.201105730

[31] Li K., Song J., Xu M., Kuga S., Zhang L., Cai J.: Extraordinary reinforcement effect of three-dimensionally nanoporous cellulose gels in poly( $\varepsilon$-caprolactone) bionanocomposites. ACS Applied Materials and Interfaces, 6, 7204-7213 (2014). https://doi.org/10.1021/am500337p

[32] Li K., Huang J., Gao H., Zhong Y., Cao X., Chen Y., Zhang L., Cai J.: Reinforced mechanical properties and tunable biodegradability in nanoporous cellulose gels: Poly(l-lactide-co-caprolactone) nanocomposites. Biomacromolecules, 17, 1506-1515 (2016). https://doi.org/10.1021/acs.biomac.6b00109

[33] Shi Z., Huang J., Liu C., Ding B., Kuga S., Cai J., Zhang L.: Three-dimensional nanoporous cellulose gels as a flexible reinforcement matrix for polymer nanocomposites. ACS Applied Materials and Interfaces, 7, 22990-22998 (2015). https://doi.org/10.1021/acsami.5b06232

[34] Pinto E. R. P., Barud H. S., Silva R. R., Palmieri M., Polito W. L., Calil V. L., Cremona M., Ribeiro S. J. L., Messaddeq Y.: Transparent composites prepared from bacterial cellulose and castor oil based polyurethane as substrates for flexible OLEDs. Journal of Materials Chemistry C, 3, 11581-11588 (2015). https://doi.org/10.1039/C5TC02359A

[35] Borah J. S., Chaki T. K.: Exploring the simultaneous effect of organoclay and controlled peroxide curing on thermal stability of LLDPE/EMA blend. Thermochimica Acta, 529, 45-50 (2012). https://doi.org/10.1016/j.tca.2011.11.020 